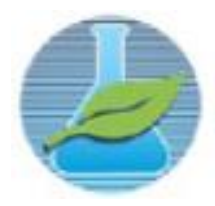

$\mathrm{JCEC} / \mathrm{REQ}^{2}$

Journal

ISSN: 2446-9416

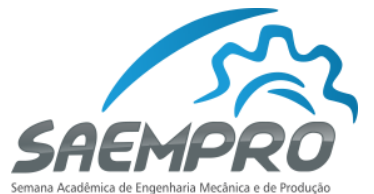

"EU, A INDÚSTRIA E O MUNDO"

08 a 11 de novembro de 2016 no campus Viçosa da UFV

Departamento de Engenharia de Produção e Mecânica - DEP

Universidade Federal de Viçosa - UFV

\title{
APLICAÇÃO DE FERRAMENTAS DA QUALIDADE: UM ESTUDO DE CASO SOBRE A SATISFAÇÃO DOS CLIENTES DE UMA AGÊNCIA BANCÁRIA DE GOVERNADOR VALADARES - MG
}

\author{
Carlos Antônio Gonçalves Rosado, Geisiely Chaves Carrijo, Leonardo de Souza Figueredo, \\ Túlio Pereira Veiga \\ Instituto Federal de Minas Gerais - Campus Governador Valadares \\ Avenida Minas Gerais, 5189, Ouro Verde - 35057-760 - Governador Valadares - MG \\ carlos.rosado@ifmg.edu.br, geisielycarrijo@hotmail.com, leonardosfsouza@gmail.com, \\ tuliopveiga@gmail.com
}

\section{INTRODUÇÃO}

Com o advento do capitalismo e da concorrência cada vez mais acirrada, as organizações passaram a almejar cada vez mais alcançar uma maior fatia do mercado, para tanto, fez-se necessário que as mesmas passassem a cumprir alguns requisitos básicos da qualidade. Seguindo essa linha de raciocínio, surge o questionamento sobre a funcionalidade das ferramentas da qualidade para a melhoria dos processos. Como a utilização das ferramentas podem contribuir para a melhoria da qualidade na prestação de serviços?

Para Rocha (2007) para que as empresas possam suprir as expectativas dos clientes em relação a qualidade dos produtos e serviços, precisa haver investimentos cada vez maiores em sistemas de gestão da qualidade a fim de permitir a permanência da empresa em um mercado cada vez mais competitivo.

Neste contexto, o presente trabalho mostra o uso de ferramentas da qualidade para selecionar, estabelecer, ordenar e propor soluções para os problemas que interferem na satisfação dos clientes durante $\mathrm{o}$ atendimento de uma empresa do setor bancário da cidade de Governador Valadares-MG.

\section{DESENVOLVIMENTO}

O trabalho se deu através de um estudo de caso. Para torná-lo possível, foi necessária uma pesquisa de satisfação dos clientes em relação ao atendimento prestado na empresa denominada, por motivos de sigilo, Empresa Alfa.

Foi aplicado um modelo de questionário (Fig. 1) elaborado pela empresa, neste continham perguntas direcionadas aos clientes que utilizam os serviços da empresa. Por meio do questionário (Fig. 1), juntamente com visitas a instituição alvo do estudo foi possível detectar que nela ocorria os problemas que são descritos abaixo (Tab. 1) em ordem de maior ocorrência: 


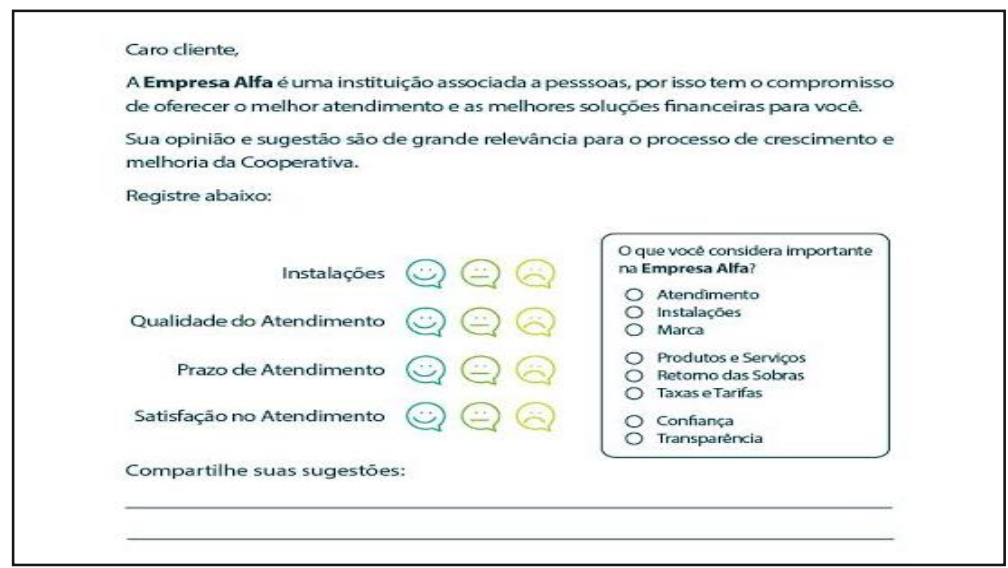

Figura 1 - Questionário aplicado (Empresa Alfa).

Tabela 1 - Dados coletados (Autores).

\begin{tabular}{|c|c|c|c|}
\hline Razões & Bom & Regular & Ruim \\
\hline Instalações & 47 & 2 & 1 \\
\hline $\begin{array}{c}\text { Qualidade de } \\
\text { Atendimento }\end{array}$ & 42 & 5 & 15 \\
\hline Prazo de Atendimento & 30 & 1 & 6 \\
\hline $\begin{array}{c}\text { Satisfação no } \\
\text { Atendimento }\end{array}$ & 43 & 10 & 28 \\
\hline Total & 162 & & 6 \\
\hline
\end{tabular}

Utilizando o Gráfico de Pareto (Fig. 2), que consiste em ser uma ferramenta de extrema importância para análise de frequência dos problemas, fica evidente que a maioria dos clientes $(53,57 \%)$ acham ineficiente o Prazo do Atendimento. Isto é mostrado no gráfico a seguir:

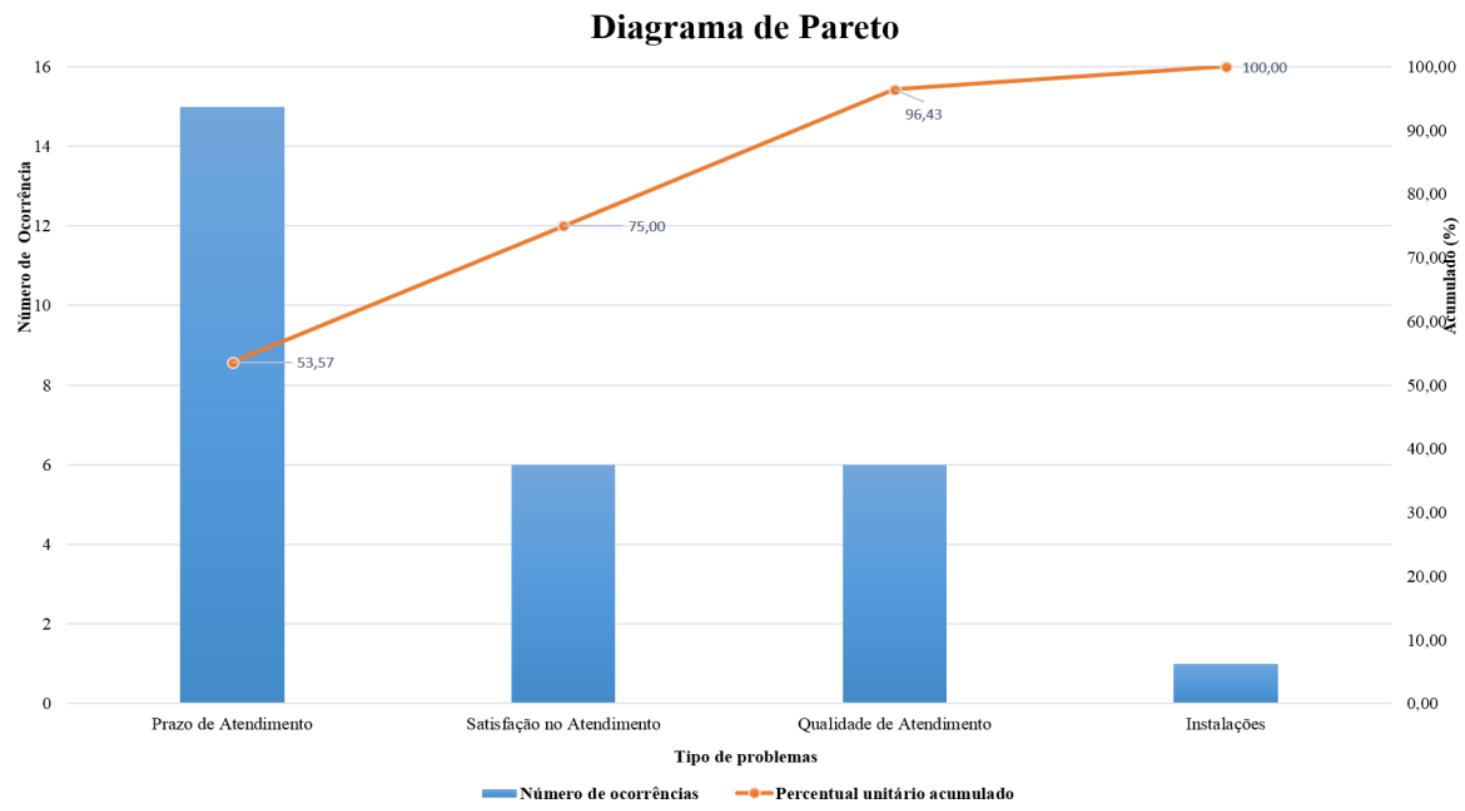

Figura 2 - Diagrama de Pareto utilizando os dados coletados (Autores). 
Não obstante, foi necessária também a utilização do Diagrama de Ishikawa (Fig. 3) tendo em vista que esta ferramenta auxilia na determinação das causas que levam ao problema.

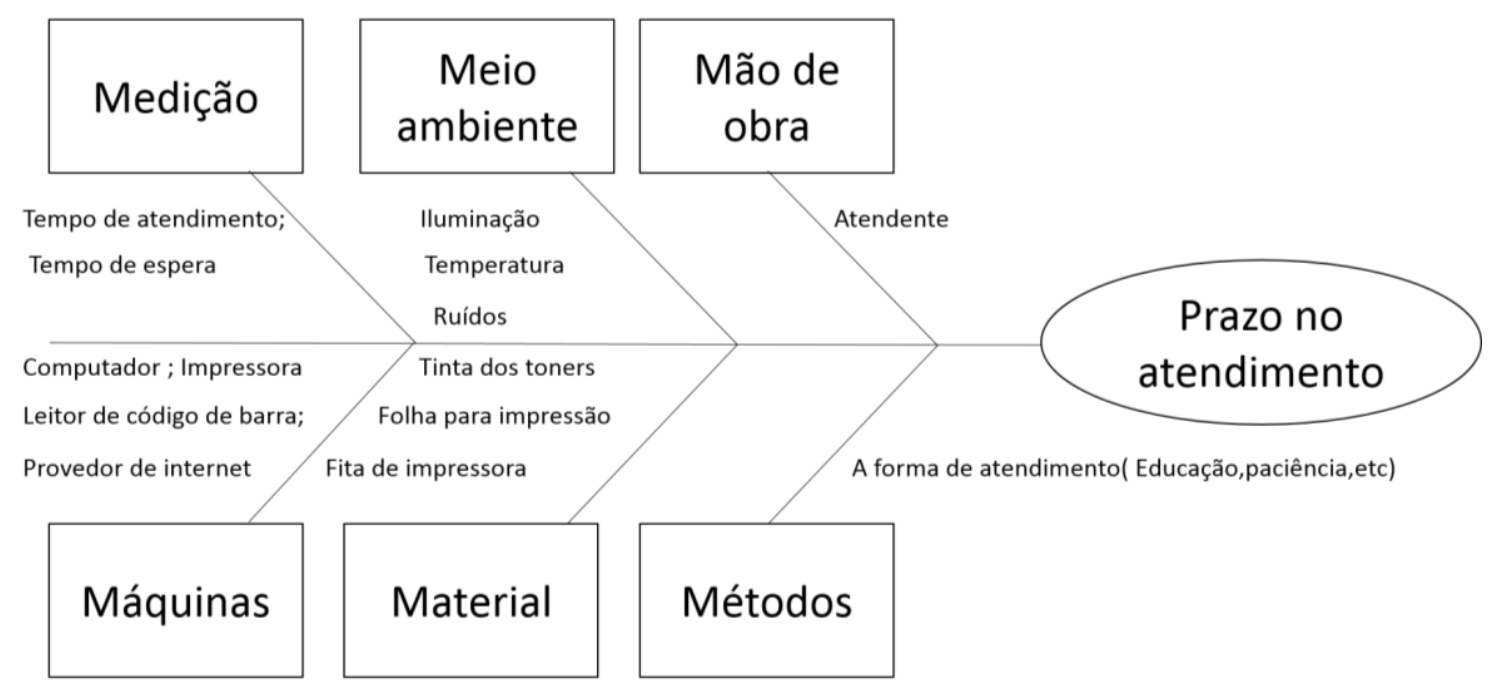

Figura 3 - Diagrama de Ishikawa utilizado para determinar as causas do problema (Autores).

\section{CONSIDERAÇÕES FINAIS}

Com base nos resultados apresentados, pode-se concluir que segundo o Diagrama de Pareto o principal problema está relacionado ao prazo de atendimento ao cliente da Empresa Alfa. Além disso, baseado no Diagrama de Ishikawa é notório que este problema pode ser derivado do tempo de atendimento, do tempo de espera para o atendimento, da forma como o cliente é atendido pelo funcionário, além de problemas relacionados a máquinas tais como computadores, impressora e leitores de códigos de barra.

No entanto, é necessário ressaltar que a conclusão obtida pode não ser um resultado verdadeiro, tendo em vista que o questionário aplicado (Fig. 1) possui falhas no que se refere às especificações dos tópicos analisados, por exemplo, quando pergunta sobre o prazo de atendimento, não fica claro se esse prazo é o tempo de espera na fila para ser atendido ou se é o tempo que o atendente demora para processar os documentos solicitados. Dessa forma, foi sugerido que a empresa adotasse um novo modelo de questionário, com questões mais objetivas e claras e sem dupla interpretação. Esse se faz necessário para uma conclusão mais precisa e assim determinar de fato as causas que levam ao efeito indesejado ou problemas.

\section{REFERÊNCIAS}

ROCHA, M. Q. B. "Elaboração de indicadores e uso de ferramentas da qualidade na execução de obras prediais". Dissertação apresentada ao Programa de Pós-graduação em Engenharia Civil da Universidade Estadual do Rio de Janeiro UERJ, 2007. 193 p. 